Thorax (1975), 30, 355.

\title{
Pulmonary arteriovenous fistula presenting as spontaneous haemothorax
}

\author{
B. S. S P E A R, L. S U L L Y, a n d C. T. LE W I S \\ Department of Cardio-Vascular and Thoracic Surgery, The London Hospital
}

\begin{abstract}
Spear, B. S., Sully, L., and Lewis, C. T. (1975). Thorax, 30, 355-356. Pulmonary arteriovenous fistula presenting as spontaneous haemothorax. We record a case of pulmonary arteriovenous fistula presenting in a dramatic and unusual way. These lesions are generally diagnosed clinically by consideration of their associated features. In this case these were all absent, and the patient presented with a spontaneous haemothorax as an isolated finding. When blood is found on aspiration of the pleural cavity it generally represents bloodstained effusion (trauma excluded), and by far the commonest cause is bronchogenic carcinoma. Less frequently, however, aspiration of blood may represent spontaneous intrapleural bleeding without effusion (spontaneous haemothorax), and a rare cause of this situation is pulmonary arteriovenous fistula. We record this case to demonstrate that innocent pulmonary arteriovenous fistulae can masquerade as carcinoma.
\end{abstract}

Pulmonary arteriovenous fistulae are rare. The cardinal clinical features, depending on size and degree of shunt, include cyanosis, clubbing, polycythaemia, dyspnoea, and extracardiac murmur in the absence of congenital heart disease (le Roux, 1959). The murmur, which is systolic, is louder on deep inspiration and softer on expiration. Pulmonary arteriovenous fistulae are more common in males, symptoms usually occurring in the third decade (Erf et al., 1949). Multiple cutaneous and mucosal lesions are frequent accompaniments (Bean, 1958), and a family history is common (Hodgson et al., 1959). These two latter features comprise the syndrome of hereditary haemorrhagic telangiectasia.

\section{CASE REPORT}

A 71-year-old woman was admitted in July 1974 complaining of right-sided chest pain of acute onset and pleuritic in nature. She had collapsed and on arrival was hypotensive with a tachycardia for a brief period. There had been vomiting since the onset of the pain and a cough productive of white sputum streaked finely with blood for two days. There were no other symptoms and no weight loss. There was no relevant past or family history. The patient had not had a chest radiograph before admission.

Clinically there were signs of a right-sided pleural effusion and of mild congestive cardiac failure. Examination was otherwise negative, in particular she had none of the cardinal features mentioned above. A chest radiograph confirmed the presence of a large right-sided pleural effusion. Diagnostic pleural aspiration revealed heavily bloodstained fluid on two occasions. Neoplastic cells were not identified in the fluid, nor were they present in three samples of sputum.

At bronchoscopy the right stem bronchus was narrowed and its mucosa was haemorrhagic. No tumour was seen. Biopsy showed non-specific changes only.

At right thoracotomy there was much heavily bloodstained free fluid in the pleural cavity. There were no abnormal lymph nodes. A firm, diffuse mass was palpable in the lower lobe, encroaching close to the fissure with the middle lobe. An intrapleural bleeding was identified at the apex of the mass. Routine middle and lower lobectomy was performed. Histology (Dr. D. Pollock) showed an area of recent haemorrhage in the lower lobe, in the fibrous wall of which were large blood vessels, some showing thrombosis and intimal thickening. The mass, which abutted the surface of the lobe, measured $2 \times 2 \times 1.5 \mathrm{~cm}$. The appearances were of an arteriovenous fistula.

The patient made a good recovery, was discharged on the 12th postoperative day, and was well at follow-up one month later. 


\section{COMMENT}

The presumptive clinical and operative macroscopic diagnosis was of an operable bronchogenic carcinoma. Moreover, as the lesion was oozing blood from its surface, it was considered safer to remove it. The diagnosis of carcinoma was by far the likeliest, given the circumstances. We assume that the arteriovenous fistula bled from its surface causing the pleuritic pain and short-lived signs of internal bleeding described by Perry (1938). The haemoglobin and haematocrit of the fluid were not estimated, so its exact nature-whether blood alone or blood mixed with effusion-cannot be stated.

Intrabronchial rupture causing haemoptysis is a well recognized complication of pulmonary arteriovenous fistula occurring in $25 \%$ of cases (Dalton et al., 1967). Intrapleural rupture is distinctly rare, and only a few cases have been reported (Wilkens, 1917; Rodes, 1938; Erf et al., 1949; Armentrout and Underwood, 1950; Heyde, 1954; Puriel and Muras, 1957; Brummelkamp, 1961; Dalton et al., 1967; van Ginneken, 1973). All these reported patients, however, displayed other presenting features, suggesting the diagnosis of arteriovenous fistula.

We record this case to demonstrate that bloody fluid in the pleural cavity, in the absence of trauma, need not always imply cancer.

We are grateful to Mr. Geoffrey Flavell for his permission to report this case.

\section{REFERENCES}

Armentrout, H. L. and Underwood, F. G. (1950). Familial hemorrhagic telangiectasia with associated pulmonary arteriovenous aneurysm. American Journal of Medicine, 8, 246.

Bean, W. B. (1958). Vascular Spiders and Related Lesions of the Skin. Blackwell, Oxford.
Brummelkamp, W. H. (1961). Unusual complicatio $\overrightarrow{\overline{\vec{D}}}$ of pulmonary arteriovenous aneurysm: intrespleural rupture. Diseases of the Chest, 39, 218

Dalton, M. L., Goodwin, F. C., Bronwell, A. W., a Rutledge, R. (1967). Intrapleural rupture तf arteriovenous aneurysm. Diseases of the Chear 52, 97.

Erf, L. A., Foldes, J., Piccione, F. V., and Wagnen F. B. (1949). Pulmonary hemangioma with pulfmonary artery-aortic septal defect. American Heart Journal, 38, 766.

Heyde, E. C. (1954). Hereditary hemorrhagic telan ectasia: A report of pulmonary arteriovenoßู fistulae in mother and son: medical (hormonfy and surgical therapy of this disease. Annals Internal Medicine, 41, 1042.

Hodgson, C. H., Burchell, H. B., Good, C. A., au Clagett, O. T. (1959). Hereditary hemorrhagd telangiectasia and pulmonary arteriovenots fistula. New England Journal of Medicine, 261, 625 .

Perry, K. M. A. (1938). Spontaneous haemothora苘 Lancet, 2, 829.

Puriel, P. and Muras, O. (1957). Aneurismas arteriol venosos de pulmón. El Torax, 6, 101.

Rodes, C. B. (1938). Cavernous haemangiomas of the lung with secondary polycythemia. Journal of $t$ American Medical Association, 110, 1914.

le Roux, B. T. (1959). Pulmonary arteriovenog fistulae. Quarterly Journal of Medicine, N. $28,1$.

van Ginneken, P. J. (1973). A rather rare complic tion of pulmonary arteriovenous fistula. Archivum chirurgicum Neerlandicum, 25, 27.

Wilkens, G. D. (1917). Ein Fall von multiplen Pư monalisaneurysmen. Beitrage Zur Klinik der Tuberkulose und spezifischen TuberkuloseForschung, 38, 1.

Requests for reprints to: C. T. Lewis, F.R.C.S Department of Cardiothoracic Surgery, Londg Hospital, Whitechapel, London E1 1BB. 